\title{
Substrate-induced Acceleration of Lactase Synthesis in Fetal Rat Intestine
}

\author{
I. L. LIFRAK, R. LEV, ${ }^{(26)}$ AND A. V. LOUD \\ Department of Pathology, New York Medical College, Basic Sciences Building, Valhalla, New York, USA
}

\section{Extract}

Twenty milligrams of lactose were injected into the amniotic sacs of fetuses in one uterine horn and $20 \mathrm{mg}$ glucose were injected into the amniotic sacs of fetuses in the opposite uterine horn of six rats on days $17-19$ of pregnancy. Two or 3 days later the pregnant animals were killed and segments of jejunum obtained from their fetuses were homogenized in water. Assays for lactase and protein determinations were performed on these homogenates. Lactase values were significantly higher in the lactose-injected group than in fetuses receiving glucose (Table 2 ), $P<0.005$. Thus, fethlintestinal lactase activity can be increased by exposure to the substrate lactose during late fetal life.

\section{Speculation}

Administration of an appropriate substrate in utero may prove useful in selected cases of human fetal enzyme deficiency. The intra-amniotic route could be more effective than maternal injection because it provides direct access to the fetus and thereby permits the use of a smaller dose and minimizes or completely avoids possible maternal and/or placental inactivation of the substrate.

There is disagreement whether the production of intestinal lactase is determined primarily by genetic or by substrate-dependent mechanisms $(11,20)$. The former hypothesis is supported by the observation in rabbits that elimination of circulating maternal lactose by mastectomy before breeding does not prevent the normal rise in intestinal lactase in the developing fetuses (5). Furthermore, lactase develops normally in isografts of fetal mouse intestine which are placed under the renal capsule of adult nonpregnant mice and which are thus never exposed to intralumi. nal lactose (7). On the other hand, several investigators have found that dietary lactose can specifically induce lactase synthesis ( $1-3$, 9 ), although others have denied this $(8,10)$.

In the present study we have attempted to accelerate intestinal lactase synthesis in the fetal rat by exposing the fetus to lactase injected directly into the amniotic sac 4-5 days before birth. At this stage relatively low enzyme values are normally found (5) and rapid morphologic and histochemical differentiation of intestinal epithelium is taking place. Swallowing of amniotic fluid and the intestinal uptake of compounds injected into the fluid have been demonstrated in the fetal rat $(13,17,18,21)$.

\section{MATERIALS AND METHODS}

The uterine horns of 11 rats in the 17th to 19th day of pregnancy were exposed surgically. In eight of these rats the amniotic sacs of the fetuses from one horn were injected with $0.1 \mathrm{ml}$ of a $20 \%$ solution of $\beta$-D-lactose (22) in distilled water and control fetuses in the opposite uterine horn received intraamniotic injections of 0.1 $\mathrm{ml} 20 \%$ glucose. Fetuses from six of these eight rats were removed 2-3 days later (Tables 1 and 2), whereas in two rats the fetuses were removed 1 day later.

In two of the remaining three rats $20 \%$ glucose was injected into the amniotic sacs of one horn and either physiologic saline was injected into the other horn or the fetuses of that horn received no injection. The third rat received saline in one horn and no injections in the opposite horn. These fetuses were removed 3 days later.

At the time of sacrifice the pregnant rats were reanesthetized and the fetuses removed rapidly and weighed. Deat or unusually small fetuses (i.e., $0.5 \mathrm{~g}$ or more below the mean fetal weight of the injected group) were excluded. Full thickness strips of jejunum measuring $6-10 \mathrm{~cm}$ were taken from each fetus, weighed separately, and pooled into experimental (lactose-injected) and control (glucose-injected) groups. It was found that at least two jejunal specimens were generally necessary to provide adequate material to perform the assays. In instances where larger numbers of fetuses $(>5)$ in one horn were injected with lactose, these were subdivided into two groups in order to obtain more data and to assess the effects of possible biologic and technical variables in identically treated fetuses. These tissues were then homogenized in the cold $\left(4^{\circ}\right)$ in distilled water $(1 \mathrm{ml} / 30 \mathrm{mg}$ tissue $)$, using an Ultra-Turrax

Table 1. Effect of intra-amniotic lactose injection on fetal jejunal lactase activity: Detailed data

\begin{tabular}{|c|c|c|c|c|c|c|c|c|c|c|c|c|c|c|c|}
\hline & \multicolumn{15}{|c|}{ Substrate injected into pregnant rats } \\
\hline & \multicolumn{2}{|c|}{ Rat 1} & \multicolumn{3}{|c|}{ Rat 2} & \multicolumn{3}{|c|}{ Rat 3} & \multicolumn{3}{|c|}{ Rat 4} & \multicolumn{2}{|c|}{ Rat 5} & \multicolumn{2}{|c|}{ Rat 6} \\
\hline & $\mathbf{L}$ & G & $\mathbf{L}$ & $\mathrm{L}$ & G & L & $\mathbf{L}$ & G & $\mathbf{L}$ & $\mathbf{L}$ & G & $\mathbf{L}$ & G & $\mathbf{L}$ & G \\
\hline No. of fetuses excluded ${ }^{2}$ & 0 & 0 & 1 & $\vdots 1$ & 1 & 0 & 0 & 0 & 1 & 0 & 1 & 0 & 1 & 0 & 1 \\
\hline Mean weight $(\mathrm{g})$ of in- & 3.98 & 3.62 & 3.32 & 3.21 & 3.36 & 3.78 & 3.81 & 4.15 & 3.73 & 3.85 & 3.98 & 3.80 & 3.78 & 4.70 & 4.27 \\
\hline cluded fetuses $\pm S E M$ & \pm 0.14 & \pm 0.15 & \pm 0.07 & \pm 0.07 & \pm 0.06 & \pm 0.08 & \pm 0.21 & \pm 0.12 & \pm 0.22 & \pm 0.11 & \pm 0.15 & \pm 0.05 & & \pm 0.23 & \pm 0.16 \\
\hline
\end{tabular}

${ }^{1}$ L: Lactose; G: glucose.

${ }^{2}$ Includes both dead and small fetuses.

${ }^{3}$ Expressed as micromoles of glucose liberated per min per mg of protein. The values shown represent determinations made on pooled jejuna. 
homogenizer, and stored at $-200^{\circ}$. Assays for lactase were carried out according to the method of IDahligivist (4) using $0.056 \mathrm{M}$ lactose as substrate in $0.1 \mathrm{M}$ maleate buffer, $\mathrm{pH}$ 6.0. After incubation with this substrate for $1 \mathrm{hr}$ at $37^{\circ}$, the reaction was stopped by adding Tris-glucose oxidase reagent (23) and the amount of glucose present was determined after 1 additional $h r$ incubation in the latter medium. Protein was determined according to Lowry et al. (15). The significance of differences in lactase activity between lactose- and glucose-injected groups was evaluated statistically using Student's $t$-test.

\section{RESULTS}

Jejuna from fet uses receiving intraamniotic injections of lactose 2 or 3 days eartier showed significantly higher lactase activity, expressed as micromoles of glucose liberated per min per $\mathrm{mg}$ of protein, than jejuna from fetuses receiving isocaloric amounts of glucose. Data forthese animals are presented in Table 1, where the consistent elevation of lactase values is evident in each of the nine lactose groups from six pregnant rats. If these data are pooled (Table 2) the mean jejunal lactase activity per fetus \pm SEM for the nine lactose groups (29. fetuses) is found to be $1.81 \pm 0.15 \mathrm{U}$ whereas for the six groups raceiving glucose ( 16 fetuses) jejunal lactase activity is $0.85 \pm 0.16 \mathrm{U}$, a difference that is significant at $P<0.005$.

The mean jejunal protein values per fetus for the lactose-injected fetuses was $0.93 \mathrm{mg} / \mathrm{ml}$ original homogenate (range $0.52-1.32 \mathrm{mg}$ ) and for the glucose group: was $0.90 \mathrm{mg} / \mathrm{ml}$ (range $0.55-1.28 \mathrm{mg}$ ). The mean fetal body weight ffor the lactose group was $3.77 \mathrm{~g}$ and for the glucose group was $3.91 \mathrm{~g}$; in no case did the body weights of the included fetuses in the lactose and glucose groups from the same mother vary by more than $10 \%$.

In the three pregnant rats which did not receive lactose, no differences in jejunal lactase activity were found between fetuses receiving glucose $(\bar{\chi}=0.61)$ and those receiving either saline or no injections $(\bar{\chi}=0.62)$ (Table 3). Jejuna obtained from fetuses 1 day

Table 2. Effect of intra-amniotic lactose injection on fetal jejunal lactase activity: Summarized data

\begin{tabular}{lcc}
\hline & \multicolumn{2}{c}{ Substrate injected } \\
\cline { 2 - 3 } & $\mathrm{L}$ & $\mathrm{G}$ \\
\hline $\begin{array}{l}\text { No. of fetal jejuna pooled } \\
\text { No. of fetuses excluded }\end{array}$ & 29 & 16 \\
Mean weight (g) of included fetuses \pm & $3.77 \pm 0.09$ & $3.91 \pm 0.10$ \\
$\quad$ SEM & & $4(20 \%)$ \\
Units of lactase activity ${ }^{3} \pm$ SEM & $1.81 \pm 0.15$ & $0.85 \pm 0.16$ \\
\hline & & \\
${ }^{1}$ L: lactose; G: glucose. & & \\
${ }^{2}$ Includes both dead and small fetuses. \\
${ }^{3}$ Expressed as micromoles of glucose liberated :per min per $\mathrm{mg}$ of \\
protein.
\end{tabular}

after injection: of lactose failed to show increased lactase values when compared" with the glucose-injected controls.

\section{DISCUSSION}

The most reasonable explanation for the increase in jejunal lactase values in fetuses receiving lactose is that this is the result of increased enzyme synthesis resulting from exposure to that specific substrate. An increase in the absolute, but not relative, amount of intestinal lactase has been ascribed to a nonspecific proteinstimulating effect of lactose (8). This explanation cannot obtain in the present study because we found a relative increase in the enzyme concentration and found no significant differences in the protein values between the lactose-and glucose-injected groups.

The range of lactase values in fetuses receiving the same substrate was considerable. Biologic factors that may be responsible for this include variation in size and number of fetuses, in fetal swallowing rates and in the protein-synthesizing capacity of the fetal jejunum, and the effects of anesthesia. Intra-amniotic injection, per se, however uniformly performed, may also account for variability, as suggested by the occurrence of dead and small fetuses in both glucose and lactose groups (Table 1). Some of these variables may be minimized by the use of control (i.e, glucoseinjected) fetuses from the opposite uterine horn from the same mother. This will virtually eliminate differences in fetal age, as confirmed by fetal weights, which is important since normal fetal intestinal lactase values increase sharply with increasing fetal age just before birth (5). Thus, when the fetuses from one mother are considered, it is apparent (Table 1) that the lactase values, despite some variation within groups receiving the same substrate, are consistently higher in the lactose-injected than in the glucoseinjected fetuses.

The interval between substrate exposure and increased enzyme levels is much shorter in the fetus than in the weanling or older rat, in which at least 5 weeks $(1,3,9)$ are required to produce a substantial effect using oral lactose concentration similar to those we used.

The substrateddependent increase in lactase reported here may have relevance to studies of enzyme systems in fetal intestine (16), lung $(6,12)$, and liver $(19)$ which appear capable of reacting to other types of inducers. It has even been shown that treatment of pregnant women with steroids near term reduces the incidence of the respiratory distress syndrome in the newborn (14), presumably because of induction of fetal pulmonary surfactant synthesis.

\section{SUMMARY}

Twenty milligrams of lactose were injected into the amniotic sacs of fetuses in one uterine horn in rats on days 17-19 of pregnancy and $20 \mathrm{mg}$ glucose were administered intraamniotically to fetuses in the opposite uterine horn. Two or 3 days later, the fetal jejunal lactase levels were significantly higher $(P<0.005)$ in the lactose-injected fetuses than in the glucose-injected control fetuses.

Table 3. Jejunal lactase levels' in fétuses receiving $20 \%$ glucose, physiologic saline, or no injections 3 days earlier ${ }^{1}$

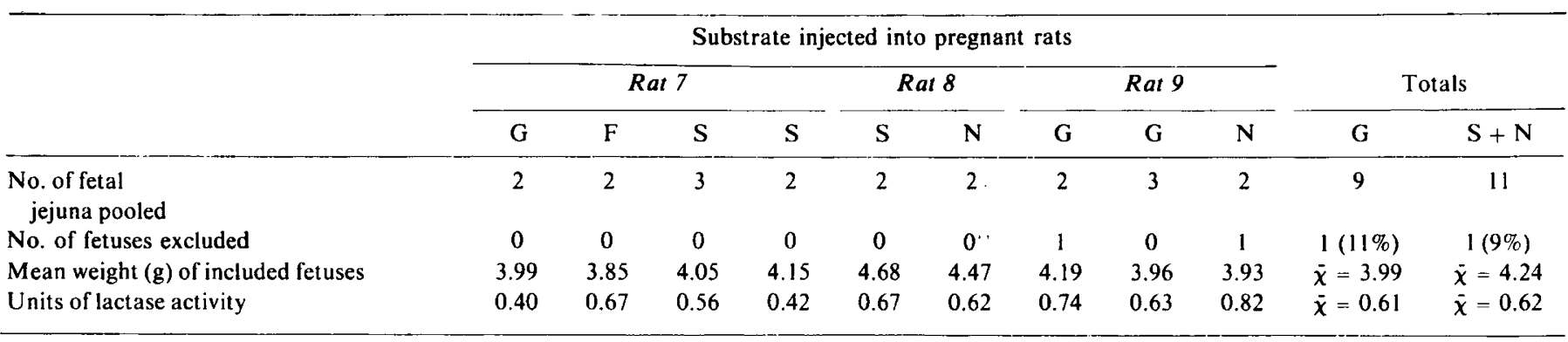

${ }^{1} \mathrm{G}$ : glucose, S: saline, $\mathrm{N}$ : not injected.

${ }^{2}$ Expressed as micromoles of glucose liberated per min per $\mathrm{mg}$ of protein. 


\section{REFERENCES AND NOTES}

1. Bolin, T. D., McKern, A., and Davis, A. E.: The effect of diet on lactase activity in the rat. Gastroenterology, 60: 432 (1971).

2. Broitman, S. A., Thalenfeld, B. E., and Zamcheck, N.: Alterations in gut lactase activity in young and adult rats fed lactose. Fed. Proc., 27: 573 (I968)

3. Cain, G. D., Moore, P., Jr., Patterson, M., and McElveen, M. A.: The stimulation of lactase by feeding lactose. Scand. J. Gastroenterol., 4: 545 (1969).

4. Dahlqvist, A.: Assay of intestinal disaccharidases. Anal. Biochem., 22: 99 (1968).

5. Doell, R. G., and Kretchmer, N.: Studies of small intestine during development. I. Distribution and activity of $\beta$-galactosidase. Biochim. Biophys. Acta, 62: 353 (1962)

6. Farrell, P. M., and Zachman, R. D.: Induction of choline phosphotransferase and lecithin synthesis in the fetal lung by cortiocosteroids. Science, 179: 297 (1973).

7. Ferguson, A., Gerskowitch, V. P., and Russell, R. I.: Pre- and postweaning disaccharidase patterns in isografts of fetal mouse intestine. Gastroenterology, 64: 292 (1973).

8. Fischer, J. E.: Effects of feeding a diet containing lactose upon $\beta$-d-galactosidase activity and organ development in the rat digestive tract. Amer. J. Physiol. 188: 49 (1957)

9. Girardet, P., Richterich, R., and Antener, I.: Adaptation de la lactase intestinale à l'administration de lactose chez le rat adulte. Helv. Physiol. Pharmacol. Acta, 22: 7 (1964).

10. Knudsen, K., Bradley, E. M., Lecocq, F. R., Bellamy, H. M., and Welsh, J. D.: Effect of fasting and refeeding on the histology and disaccharidase activity of the human intestine. Gastroenterology, 55: 46 (1968).

11. Koldovsky, O.: Development of the Functions of the Small Intestine in Mammals and Man (Karger, White Plains, N. Y., 1969)

12. Kotas, R. V., and Avery, M. E.: Accelerated appearance of pulmonary surfactant in the fetal rabbit. J. Appl. Physiol., 30: 358 (1971).
13. Lev, R., and Orlic, D.: Protein absorption by the intestine of the fetal rat in utero Science, 177: 522 (1972).

14. Liggins, G. C., and Howie, R. N.: A cont rolled trial of antepart um glucocorticoid treatment for prevention of the respiratory distress syndrome in premature infants. Pediatrics, 50: 515 (1972).

15. Lowry, O. H., Rosebrough, N. J., Farr, A. L., and Randall, R. J.: Protein measurement with the Folin phenol reagent. J. Biol. Chem., 193: 265 (1951).

16. Moog, F., and Richardson, D.: The functional differentiation of the small intestine. IV. The influence of adrenocortical hormones on differentiation and phosphatase synthesis in the duodenum of the chick embryo. J. Exp. Zool. 130: 29 (1955).

17. Orlic, D., and Lev, R.: Fetal rat intestinal absorption of horseradish peroxidase from swallowed amniotic fluid. J. Cell. Biol., 56: 106 (1973).

18. Orlic, D. Lev, R and Rosenthal, W S . Fetal rat utilization of ${ }^{55} \mathrm{Fe}$ absorbed by fetal intestine from swallowed amniotic fluid. Blood, 43: 429 (1974).

19. Pantuck, E., Conney, A. H., and Kuntzman, R.: Effect of phenobarbitat on the metabolism of pentobarbital and meperidine in fetal rabbits and rats. Biochem. Pharmacol., 17: 1441 (1968).

20. Rosenzweig, N. S.: Adult lactase deficiency: Genetic control or adaptive response? Gastroenterology, 60: 464 (1971).

21. Williams, R. J., and Beck, F.: A histochemical study of gut maturation. J. Anat. 105: 487 (1969).

22. Eastman Organic Chemicals, Rochester, N. Y.

23. Worthington Biochemical Corp., Freehold, N. J.

24. The authors are grateful to Dr. Sara Schiller for her suggestions concerning the lactase assays. This work was supported by Grant no. 1-355 from the National Foundation-March of Dimes.

25. Requests for reprints should be addressed to: R. Lev, M.D. Department of Pathology, New York Medical College, Basic Sciences Building, Valhalla, N. Y. 10595 (USA).

26. Accepted for publication September 29, 1975.
Amino acids brain development glucose metabolism lipids malnutrition

\title{
Brain Glucose Utilization in Undernourished Rats
}

\author{
H. PETER CHASE, (40) DENIS O. RODGERSON, WARREN LINDSLEY, JR., \\ THEODORE THORNE, AND GEOFFREY CHEUNG \\ University of Colorado Medical Center, Department of Pediatrics, B. F. Stolinsky Laboratories, \\ Denver, Colorado, USA
}

\section{Extract}

The in vivo incorporation of radioactivity from $\left[U-{ }^{14} \mathrm{C}\right]$ glucose was reduced in undernourished rat pups at ages 6,10 , and 17 days for brain lipids, and at age $\mathbf{1 0}$ days for brain amino acids. Brain glucose concentrations were lower at age 20 days (controls $1.58 \pm$ 0.26 vs. test $1.14 \pm 0.07 \mu \mathrm{mol} / \mathrm{g}$ ) but other alterations in brain glucose, glycogen, ATP, or phosphocreatine concentrations were not found.

Brain mitochondrial glutamate dehydrogenase astivity was $\mathbf{2 1} \%$ and $30 \%$ lower in undernourished animals at ages 10 and 20 days, respectively. Brain mitochondrial and supernatant isocitrate dehydrogenase activities and pyruvate kinase activity were similar for undernourished and control animals.

Brain glycogen levels were 2-4 times higher in late fetal and newborn control animals (13.6 and $15.3 \mu \mathrm{mol} / \mathrm{g}$ ) than in older animals (4.2-5.7 $\mu \mathrm{mol} / \mathrm{g})$. Brain glucose, ATP, and phosphocreatine levels increased from the 15-day fetus to the newborn, but thereafter showed no further increase.

\section{Speculation}

Reduced utilization of glucose to form lipids could account for the previously described reductions in brain lipids resulting from undernutrition.

The effects of postnatal undernutrition on brain biochemical development and on intellectual development have been summarized in several recent reviews $(5,10,12,31)$. Studies in experimental animals and in humans have shown alterations in brain weight, cell number, and in myelin lipids as a result of undernutrition. The mechanism of these alterations is as yet unknown, but could involve reduced brain glucose utilization. Glucose is the primary substrate utilized by the human or experimental animal infant brain as a source of energy, and is an important substrate in the formation of many brain intermediates. Low blood glucose levels have also been shown to be common in children dying of malnutrition (30). The present paper reports studies in undernourished and control rat pups of brain and liver utilization of 